\title{
ANÁLISIS DE LA SITUACIÓN SANITARIA Y HÁBITAT DE LOS GITANOS ONUBENSES
}

\author{
ANA ESMERALDA RIZO LÓPEZ \\ PILAR BLANCO MIGUEL \\ Departamento de Sociología y Trabajo Social. Universidad de Huelva.
}

\section{ABSTRACT}

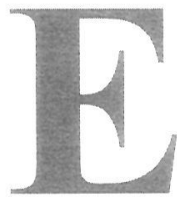

I presente artículo recoge un análisis detallado, por zonas geográficas e incluso municipios, de la ubicación y condiciones generales de las viviendas de la comunidad gitana onubense, así como de aspectos relativos a la salud que se han detectado dentro de este grupo. Veremos cómo la endogamia facilita la aparición y difusión de enfermedades tales como la Charcot-Mary Tooth, el contacto con la ilegalidad produce alteraciones en el sistema nervioso que repercuten no sólo en la salud sino en la vida familiar y cotidiana o las situaciones de semighetto que se producen en algunos lugares, sin olvidar los campamentos instalados por gitanos extranjeros o de la propia Huelva durante las campañas de recogida de cítricos, fundamentalmente. Sin embargo, y a pesar de lo que a primera vista pudiera parecer, no hay grandes diferencias entre la situación de la comunidad gitana y el resto de los vecinos de sus municipios de igual condición socieconómica.

Claves: salud, vivienda, gitanos onubenses.

\section{INTRODUCCIÓN}

Este trabajo ${ }^{1}$ pretende recoger algunos de los resultados obtenidos en una investigación sobre el mundo gitano de la provincia onubense, finalizada en el verano de 2002 y subvencionada por la Unión Europea a través de la Excma. Diputación Provincial de Huelva. La investigación referida se encuadraba dentro del programa UNA EUROPA PARA TODOS, y en nuestro caso se llevó a cabo con el objeto de estudiar la exclusión social en la provincia. Por lo que a la metodología se refiere, hicimos básicamente uso de técnicas cualitativas, centrán-

1 Nuestro más sincero agradecimiento a la coordinadora de Unión Romaní en Huelva, Da Gema Romero Indiano. 
donos en las entrevistas en profundidad y en los grupos de discusión. Mientras las primeras tuvieron como objeto recoger información de profesionales, cuya actividad laboral está claramente relacionada con la población gitana, o de miembros de esta etnia con gran peso dentro de su comunidad, los segundos fueron imprescindibles para conocer la opinión de los propios gitanos de base.

Para la presentación de los datos obtenidos en lo relativo a la vivienda y a la situación sanitaria, hemos seguido el esquema de división provincial ofrecido por Jesús Monteagudo ${ }^{2}$, apareciendo seis zonas claramente diferenciadas: Campiña-Condado, Costa, Sierra, Andévalo, Cinturón agroindustrial y la ciudad de Huelva. Así mismo, hemos considerado pertinente hacer uso y explicitar algunas de las frases literalmente enunciadas en los grupos o por algunos de los entrevistados. A continuación, comenzamos la exposición analizando los pueblos donde existen miembros de la comunidad gitana asentados, aunque en el caso de la campiña-condado haremos mención de la situación de los gitanos inmigrantes (portugueses, rumanos y españoles) por el peso que tienen en el aumento de su población, especialmente en la época de recogida de cítricos. Con menor densidad encontramos la misma problemática en otros pueblos de la costa donde las campañas agrícolas tienen gran influencia en la economía de la zona.

\section{CAMPIÑA - CONDADO}

Con relación a las comunidades gitanas establecidas en esta zona, lo primero que cabe destacar es la pérdida de población gitana ocurrida en la última década, especialmente en La Palma del Condado, en Bonares y en Paterna del Campo. Así mismo, los núcleos mayores de esta población se concentran en Almonte, en Bollullos Par del Condado y en Rociana del Condado, presentando esta última una comunidad por encima de los doscientos miembros y características muy específicas. Realmente los problemas de integración y de mayor exclusión se encuentran en Paterna del Campo y en Rociana del Condado, donde podría hablarse de auténticos ghettos por la ubicación y falta de contacto con la mayoría de los habitantes de estos municipios. Cuando el contacto ocurre suele darse con los sectores más marginales del pueblo.

El mayor problema lo presentan los gitanos portugueses instalados en campamentos ilegales, principalmente a las afueras de Rociana del

2 Monteagudo López - Menchero, J.: Comarcalización y organización geográfica de la provincia de Huelva. Cámara Oficial de Comercio, Industria y Navegación de Huelva. Huelva. 1986. 
Condado y de Almonte por la zona del Rocío, en la Teja y en la Cañada. Sin contacto con los gitanos de estos municipios, se produce un claro rechazo social hacia ellos, tanto por parte de éstos como del resto de los habitantes de estas poblaciones. El aumento de la mendicidad y de la delincuencia ocurridos tras su llegada es el factor fundamental que origina este rechazo y aumenta el temor de los gitanos de Rociana del Condado y de Almonte a ser estigmatizados como consecuencia de hechos ajenos a ellos. No son contratados en la gran mayoría de los casos por los empresarios agrícolas, pero no dejan de acudir desde el comienzo de las campañas. Careciendo de las condiciones y de los servicios más básicos, no admiten intervención de los servicios sociales, salvo en los casos en que ellos se acercan a las oficinas para demandar alimentos o combustible. No aceptan injerencias ni en temas de sanidad ni de educación. Con higiene y alimentación precarias las enfermedades afloran, pero lo asumen como algo natural, dándose el caso, por ejemplo, de un bebé de meses que padeciendo broncolitis no pudo ser seguido en su tratamiento ya que la madre, adolescente de quince años, pidió el alta voluntaria y se negó rotundamente a cualquier cuidado por parte del personal sanitario. Alegaba que ella era la madre y sabía muy bien qué hacer con su hijo.

No son estos, sin embargo, los únicos campamentos gitanos en la zona, ya que también acampan miembros de esta etnia provenientes de la ciudad de Huelva, en muchos casos, de las Marismas del Odiel. A pesar de poseer casa propia en Huelva, y de que la distancia al Condado no es excesiva (no supera los $60 \mathrm{kms}$ ), prefiere trasladarse toda la familia al lugar de trabajo, viviendo en condiciones precarias, al carecer incluso de luz y de agua, antes que desplazarse diariamente al lugar de trabajo desde la capital. Por esta causa, se observan mujeres en los campamentos que no trabajan al cuidado de los niños más pequeños, comentándonos que seguir a su marido es su obligación como esposa según sus propias costumbres. También acceden al pueblo, en época de campaña agrícola, gitanos procedentes de otros municipios y de otras provincias, pero no plantean problemática, ya que vienen con el contrato hecho y con la vivienda adjudicada. Normalmente sólo acuden a los servicios sociales por temas de traslado de expediente y de transporte escolar.

\subsection{Vivienda}

Salvo en los casos de Paterna del Campo y de Rociana del Condado, los lugares de residencia no presentan grandes diferencias con respecto a aquellos en los que residen las capas sociales de menor poder adquisitivo. En Bollullos Par del Condado, la población gitana habita en 
su mayoría en viviendas de promoción pública, encontrándose muchos de ellos en el barrio de San Antonio y en la Avenida de la Feria, donde no se puede decir que haya grupos de marginación amplios. En Almonte se hallan dispersos por el municipio, si bien un amplio porcentaje se concentra en la Carretera del Rocío y en las calles Ramón y Cajal -en la que compraron solares y muchos edificaron sus casas-, y Feria, cercana a la carretera del Rocío y situada en lo conocido como El Chaparral. También habitan en número importante en los barrios Obrero -calle Pastorcito- y de la Constitución. En realidad, muchos de los habitantes de este último barrio han crecido en el barrio Obrero al asentarse sus padres en este lugar. El barrio de la Constitución comenzó a levantarse hace dos décadas, con una primera fase en la que se repartieron ciento setenta viviendas de promoción oficial, ampliadas en cincuenta y nueve, diez años más tarde. Aunque ambos son barrios con familias multiproblemáticas, no alcanzan los límites para que puedan ser considerados como de actuación preferente, ni existe disparidad de vidas entre las familias gitanas y no gitanas allí asentadas, como para que pueda hablarse de problemática específica gitana. Existe una gran integración por parte de la comunidad, con un importante índice además de matrimonios mixtos.

La Palma del Condado tiene dispersa a su población gitana dentro del casco urbano, aunque mayoritariamente se concentra en algunas barriadas, de las cuales sólo una puede decirse que acoja a un tipo de vida marginal. Nos referimos a la zona de 'El Calvario', donde entre las diversas familias residentes encontramos cuatro familias gitanas, pero tan sólo una de ellas tiene problemas a causa de la droga. Realmente es una problemática traída por los jóvenes, ya que los padres han sido personas trabajadoras, aunque no sobradas de recursos. Mayoritariamente viven en casas de planta baja, de las cuales algunas son antiguas y necesitadas de reforma, pero el ayuntamiento suele conceder subvenciones para su rehabilitación. De cualquier forma no es un problema exclusivo de la población gitana.

Por lo que respecta a Rociana del Condado, los gitanos de este municipio se hallan concentrados en la zona alta del pueblo. La estructura y el acondicionamiento de sus casas no son muy buenos, y algunos realmente inadecuados, debido fundamentalmente a que no existe demasiada preocupación por el tema dentro de la comunidad y a los escasos recursos de que disponen. Son propietarios de sus viviendas. El proceso que acostumbran a seguir es la compra del solar sobre el que edifican precariamente y poco a poco, a medida que van obteniendo recursos económicos y materiales, habitándola en cuanto presenta condiciones mínimas (Levantan cuatro tabiques y se casan muy jóvenes ; con lo mínimo!; incluso se han ido a vivir con la casa en 
bruto. - Trabajadora social de los Servicios Sociales Municipales de Rociana del Condado-). Sin embargo, y frente a lo que pudiera pensarse, no se da hacinamiento en las viviendas. Por otro lado, encontramos una sola familia viviendo en el centro del pueblo, pero en realidad es mixta, ella no es gitana y él vino de Extremadura, de Fregenal de la Sierra. Posteriormente, otros miembros de su familia también se han asentado en Rociana del Condado, pero no suelen tener contacto con las demás familias gitanas del pueblo y su nivel económico es mucho más alto que el de las anteriores.

Paterna del Campo presenta también una situación de agrupación de familias gitanas concentradas en un barrio -Prado San Roque-, situado en la periferia del municipio. El origen de este barrio se remonta a los años cincuenta y debe su nombre a que en este prado se edificó una ermita en honor a San Roque en el siglo XVII. Un grupo de personas con nivel económico alto, miembros de Acción Católica, decidieron a finales de los años cincuenta construir varias casas para las personas con problemas económicos. Al principio estas familias comenzaron a pagar un alquiler exiguo a la iglesia, para acabar obteniéndolas en propiedad. El resto de las viviendas que componen la barriada se levantaron ya en los años sesenta. A mediados de la década de los setenta, apareció una familia gitana, procedente de la sierra de Huelva que tras pedir cobijo a la Iglesia, obtuvo una casa en el barrio construida específicamente para ellos. Esto fue el comienzo de la llegada masiva de miembros de esta familia a la barriada y del abandono progresivo de las familias no gitanas de la misma. Hacia el año 1995, el porcentaje de población gitana residente en el barrio se elevaba por encima del $70 \%$, del cual solamente cinco familias eran oriundas del pueblo y el resto procedentes de las sierras de las provincias de Huelva y de Sevilla. De acuerdo a lo expresado por parte de la vecindad, lo que en un principio era residencia para personas de bajo nivel cultural, social y económico, acabó por convertirse en una barriada marginal y excluida, especialmente por el consumo y sobre todo por la venta de droga que comenzó a proliferar. En la actualidad, el porcentaje de familias gitanas ha descendido considerablemente ${ }^{3}$, así como el tráfico de drogas. No obstante, sigue siendo un barrio especialmente problemático, en el que se sigue consumiendo droga. La venta continúa pero ahora no se realiza dentro del barrio sino que salen a vender fuera y encontramos un grupo de miembros de etnia gitana implicados en robos en el pueblo y en los alrededores. Este grupo, por otro lado, junto con los traficantes, mantienen distancias con los demás habitantes del municipio y no participan para nada en ningún tipo de actividad colectiva. En cuanto al acondicionamiento de las viviendas, hay diferencias considerables por

Oscila entre el $20 \%$ y el $25 \%$. 
lo que respecta al interior. Si desde fuera ofrecen una imagen de claro deterioro, por dentro encontramos algunas equipadas con todos lo electrodomésticos y comodidades posibles, mientras otras ni siquiera poseen cuarto de baño privado y el aseo debe hacerse en el corral. Existe otro barrio, edificado con dinero público, en el que también se cedieron algunas viviendas a diversas familias gitanas, pero actualmente parece ser que por motivos laborales no residen en él, habiéndose trasladado parte de ellas a otros municipios del Condado.

\subsection{Salud}

El mayor problema de salud dentro de las familias gitanas, que encontramos en la zona, y por lo que se refiere al número de miembros afectados, es sin duda el policonsumo de droga, especialmente en Almonte, en La Palma del Condado, en Rociana del Condado y en Paterna del Campo, apareciendo el alcoholismo de forma más patente en Rociana del Condado. Paterna presenta múltiples casos de brucelosis (fiebres maltas), debido a la constante convivencia con el ganado sin que se preocupen de llevar a cabo la vacunación exigida por ley para estos animales.

Sin embargo, y debido a factores endógenos, sí podemos hablar de otro tipo de enfermedades que se concentran en la comunidad como son los diferentes tipos de minusvalías que hemos ido encontrando. Nos referimos al amplio número de sordomudos que observamos en Rociana del Condado, donde además aparecen algunos problemas de malformación ósea y de retraso. El porcentaje de malformaciones físicas se eleva en Almonte y en Bollullos Par del Condado. Encontramos el caso de una niña aquejada de la enfermedad de von Willebrand, de origen genético ${ }^{4}$. La característica común a estas últimas enfermeda-

La enfermedad de von Willebrand es una trombopatía que se debe a la falta del factor von Willebrand o en su caso, cuando existe, a su carácter defectuoso. Este factor, una vez generado por el endotelio es transportado también por las plaquetas. Cuando se produce la enfermedad, las plaquetas no pueden unirse al colágeno del subendotelio y se produce el tipo de hemorragia propio de la hemostasia primaria. Aparece así mismo una hemofilia de tipo A, ya que el factor von Willebrand es el encargado de transportar las moléculas del factor VIII y la hemofilia será mas o menos grave dependiendo de si falta el factor von Willebrand o éste es defectuoso y en qué grado. La fórmula para conocer el grado de la enfermedad es averiguar la ausencia o cantidad que existe en el plasma del factor VIII coagulativo, del factor von Willebrand antigénico, de la actividad de este factor, de la estructura multimérica y del RIPA. Descubierta en 1926 por un doctor finlandés, Eric Adolf von Willebrand, esta enfermedad puede presentar cuatro tipos distintos. Los dos primeros tipos pueden subdividirse en tres subtipos, aunque los tres del segundo pueden a su vez subdividirse en muchos más. De carácter hereditario como la hemofilia, se diferencia, entre otras causas, porque la enfermedad von Willebrand puede ser heredada tanto por los varones como por las mujeres. 
des es que han aparecido en familias cuya constante ha sido la endogamia, especialmente cuando el matrimonio lo componen primos hermanos.

\section{COSTA}

\subsection{Vivienda}

Ayamonte tiene su población gitana bastante dispersa por el municipio, si bien en la barriada Pozo del Camino, situada en la periferia del pueblo con dirección a Isla Cristina, se concentran seis familias. Debemos señalar que una parte de este barrio está administrado por el ayuntamiento de Ayamonte y el resto por el de Isla Cristina. Los que viven dentro del casco urbano no residen en viviendas de promoción pública excepto en el caso de una familia y el acondicionamiento deja más que desear en las casas del Pozo del Camino.

La comunidad gitana de Isla Cristina se ubica en diferentes barrios, destacándose la Barriada del Rocío, la Punta del Caimán, la barriada del Matadero y las calles Jesús del Gran Poder y España. Son todas viviendas de promoción pública. El problema fundamental en este ámbito es el amplio hacinamiento existente, agravado por la temprana edad en que contraen matrimonio -especialmente las mujeres- y por los embarazos adolescentes (Aquí habemos ahora mismo quince personas, con tres habitaciones. Un hijo está durmiendo en una habitación con la mujer, un niño pequeño de ellos y con dos hijos más, mocitos que tiene. Esto de aquí es general, hay 10, 12, 14 y más. -Varón, 45 años, sin estudios, casado, mariscador, de Isla Cristina-). Por otro lado, los alquileres, dado que es zona turística, en algunos casos, sobre todo a pie de playa, no suelen ser accesibles, ya que el beneficio obtenido durante los tres meses de verano es alto y los propietarios no desean alquilarlos todo el año. Así mismo, no hay conciencia de pago de alquiler y treinta o cuarenta mil pesetas al mes les parece abusivo, ya que están acostumbrados a precios casi simbólicos (Aquí pagamos cinco mil pesetas de piso, que no es ná, tal y cómo está hoy. El piso es de Diputación. -Varón, 45 años, sin estudios, casado, mariscador, de Isla Cristina-) y a obtener, algunos de ellos, vivienda portátil facilitada por el ayuntamiento. Otro inconveniente añadido es, sin duda, la inestabilidad y estacionalidad laboral, lo que además provoca una dependencia institucional fuerte para lo relativo al pago de la luz, del agua e incluso de alimentos. Esto último no es privativo del colectivo gitano y se extiende a la población isleña. No obstante, es notable, también, el desconocimiento en la falta de administra- 
ción de los ingresos que obtienen (Ni comprar ni alquilar se puede con lo que se gana, porque el promedio de mariscar son cuatro o cinco mil pesetas diarias y del campo son cuatro mil quinientas pesetas diarias desde las ocho hasta las cinco de la tarde. -Varón, 45 años, sin estudios, casado, mariscador, de Isla Cristina-).

En Punta Umbría el colectivo gitano se reduce a cinco familias y una que reside entre Punta Umbría y Sevilla. Por lo que al tema de vivienda se refiere, no se distinguen de las del resto de la población media del municipio, excepto dos familias que habitan en chalets y sobresalen no sólo de la población gitana sino de la media de la población mayoritaria. Hay que tener en cuenta que estas dos familias son empresarios del gremio del comercio de zapatería.

Lepe, por su parte, presenta problemas de hacinamiento por lo que a algunos miembros de su comunidad gitana se refiere. La mayoría de ellos reside en casas muy antiguas, habitadas por componentes de varias generaciones, pero no hay una queja sobresaliente sobre este particular, salvo en determinados casos muy concretos. Mientras los menos viven en casas de su propiedad, la mayoría lo hace en casas de promoción pública. Así mismo, encontramos gitanos en chabolas y en casas caídas, tratándose de gitanos procedentes de otras zonas y especialmente extranjeros, algunos de los cuales vienen a trabajar como temporeros. Los gitanos de Lepe se hallan dispersos en diferentes calles y barrios, destacando el barrio D. Ramiro, en las Colonias, en la Colombina, en la barriada Blas Infante y en la Pendola, junto con las calles Gerona, La Palma y Velarde. La calle Río Ter de la Pendola está habitada casi exclusivamente por población gitana y también es importante el número de miembros de esta comunidad en la calle Río Piedras. El acondicionamiento de las viviendas es muy variado, y entre las que se encuentran en peores condiciones, detectamos dejadez en algunos casos y falta de los mínimos elementos de higiene, como puede ser el cuarto de baño. La peor situación, en conjunto, se da en la Pendola.

En Villablanca, encontramos cuatro familias. Dos de ellas no presentan ningún tipo de problemática, mientras las dos restantes lo hacen y de forma muy variada. Estas dos últimas viven en casas de promoción pública y las anteriores habitan en casas de planta baja de su propiedad, compradas con ayuda de la Junta de Andalucía. Una de las viviendas de las familias problemáticas se encuentra en pésimas condiciones, pero hemos de remarcar que es producto del tipo de vida que en general lleva.

En Cartaya, observamos dos sectores de población gitana con formas de vida y de recursos muy diferentes. En realidad son el sector que se agrupa bajo la Asociación Romaní 'Río Piedras' y muchos miem- 
bros de la Iglesia Evangelista de Filadelfia, y otro compuesto por personas de menor nivel sociocultural y económico. Aunque se ubican de manera dispersa, la mayor concentración se produce en los barrios conocidos como la barriada Fuente del Duque, la barriada Reina Sofía y la del Lavadero. Las viviendas de las barriadas Reina Sofía y Fuente del Duque son de promoción pública. No se puede hablar de hacinamiento estrepitoso, pero sí es verdad que muchas jóvenes que se casan con quince y dieciséis años viven junto con sus padres o suegros.

\subsection{Salud.}

En Ayamonte, sólo hemos conocido un caso de retraso mental y otro importante de consumo de droga unido a prostitución. La salud de su población gitana, en general, no tiene especificidades dignas de ser destacadas. Isla Cristina presenta casos de sordomudez y de retraso madurativo, los cuales en general suelen ser consecuencia de dejadez en la niñez, por parte de los padres, sin la asistencia y tratamientos médicos básicos que acaban por agravarse y cronificarse. No hay un número de casos de enfermedad derivados de cuestiones genéticas digno de ser señalado, aunque existe. Sin embargo, hay mayores índices de retraso desde el punto de vista oficial de los que se dan en la realidad, motivados por el objeto de obtener ayudas de los servicios sociales $(; E s$ algo alucinante!, algunas familias que le dicen a los niños lo que le tienen que decir, al que le está haciendo las pruebas en Huelva, para detectarle el 33\% de minusvalía para que le den la beca. -Directora del Colegio Sebastián Urbano Vázquez de Isla Cristina--. Tienen una habilidad especial en tener el certificado de minusvalía. Suelen ponerle retraso madurativo de un cuarenta o un cincuenta por ciento, luego tú los ves y es una criatura estupenda. -Director del I.E.S. 'El Galeón'-). De cualquier manera, el mayor problema que muestra la comunidad gitana isleña está relacionado directamente con el consumo de droga, que alcanza cotas elevadísimas, como en el resto de la población del municipio, especialmente en los jóvenes. Este problema resulta evidente hasta el extremo que existen zonas como la llamada 'de los pinos', donde empieza la zona de playa, en la que se concentra el consumo y venta de droga a la luz pública, siendo visitados por Cruz Roja para facilitarles jeringuillas.

En Punta Umbría hemos encontrado una familia con graves problemas de esquizofrenia en varios de sus miembros y en otra aparecen problemas mentales en uno de sus componentes, auque no conocemos si se debe a alguna lesión concreta o se deriva del consumo de droga a lo que es adicto. Curiosamente, en un municipio donde el consumo de droga es muy alto, y donde se ubican centros como la asociación $R e-$ 
nacer-dedicada a la atención de toxicómanos-, lugares como $\mathrm{La}$ Peguera -atendido en cuanto a alimento y controles sanitarios por Cruz Roja-, el centro de rehabilitación Naím y el ayuntamiento fue pionero junto con los de Ayamonte y Huelva en la puesta en marcha del programa Ciudad sin Droga, su escasa población gitana se encuentra muy alejada, en su gran mayoría, de esta problemática.

En Lepe, encontramos un número importante de niños con deficiencias mentales, especialmente en el barrio de la Pendola, problemas claros de higiene en familias muy concretas y numerosos toxicómanos, esto último también en consonancia con la población mayoritaria.

Por cuanto a Villablanca y a Cartaya se refiere, en Villablanca sólo encontramos una familia en la que se dan diferentes casos de minusvalía físicas tales como estrabismo, sordomudez, deficiencias renales.., pero a la vez observamos gran dejadez y poca preocupación por las revisiones y por seguir tratamientos continuados. Cartaya presenta una alto índice de alcoholismo, que aunque no puede circunscribirse a su población gitana, es también muy alto en esta comunidad. Así mismo, y dentro de ésta, también se encuentran numerosos casos de consumo de droga y de ludopatía. El maltrato familiar, tanto a mujeres como a niños, suele ser frecuente derivado en la mayoría de los casos de las toxicomanías y de la ludopatía que padecen los varones.

\section{SIERRA}

\subsection{Vivienda}

Uno de los problemas principales que encontramos en Cortegana es, sin duda, el concerniente a la vivienda. Con la mayoría de la población gitana asentada en un barrio periférico, aparecen problemas de hacinamiento debido al alto índice de natalidad y a los matrimonios jóvenes que forman una nueva familia sin poder abandonar el hogar paterno. Aunque han estado más repartidos por el pueblo, lo cierto es que siempre ha habido una zona donde se ubicaba un mayor número de gitanos, en concreto hablamos de la llamada Gitanesca, barrio cercano a la plaza de toros de la localidad. Hace aproximadamente quince años, se comenzó una primera fase de construcción de casas subvencionadas por la Junta de Andalucía y en la actualidad ya se han desarrollado tres fases. Muchos de los gitanos establecidos en la Gitanesca, se trasladaron a chabolas y a casas que ellos mismos levantaron cerca del lugar donde la Junta construyó en terreno municipal, cedido por el ayuntamiento. Una vez concluida la primera fase de construcción que comentamos, gran parte de estas familias gitanas, junto con otras fami- 
lias no gitanas en parecidas circunstancias, fueron realojadas en estas viviendas y paulatinamente fue aumentando el número de realojados a medida que se incrementaba el número de casas construidas. En la actualidad la mayoría de las familias gitanas del pueblo se ubican en esta zona (barriada Eritas), mientras otras lo hacen en la calle Mendo $\mathrm{y}$ unas seis o siete familias se dispersan por el municipio, conviviendo sin problema con el resto de la población.

La principal diferencia entre las familias que viven en la calle Mendo y en la barriada Eritas es el tipo de acceso a la vivienda, mientras las primeras las tienen en propiedad las segundas están en régimen de alquiler, aunque no hayan realizado los pagos correspondientes. Precisamente esa ha sido una de las demandas prioritarias que se nos han trasladado (Nosotros las casa que tenemos er arquilá. Nos metieron ahí un tiempo como diciendo que no se pagaba ná, y al cabo de diez o doce años que vivimos ahí, que estamos viviendo ahí, nos ha venío un montón de recibos, tós que quieren lo paguemos, tós los recibos juntos. Entonces, nosotros habemos dicho a la Junta Andalucía, que queremos pagar un mes de uno que va corriendo, de este mes, y otro mes de los retrasaos. Entonces, ellos nos obligan que paguemos tós los recibos juntos, entonce eso nosotros no estamos bien con dos paros -en este caso se refiere sólo a los que cobra el matrimonio titular-, quien los tenga, que arguna veces no tenemos ni los dos paros, de pagar ahí un dineral. Pa que eso, lo que queremos hablar nosotros también, a ve si nos pué quitar la Junta Andalucía de esas cosas.., que debo cerca de un millón o dos millones, de recibos de atrás y la vivienda mía sí está bien, porque la he hecho poquito a poco eso nuevo, ;vaya!, ;tamos!, tengo una habitación pa cá niño, porque los demás lo tengo casao, tengo seis chicos y cuatro casaos, pero eso de la vivienda yo no pueo pagar. -Mujer, 42 años, sin estudios, casada, ama de casa y temporera, de Cortegana-).

Reconocieron que sí sabían que tenían que pagar el alquiler, pero que el dinero les parecía excesivo. No se han preocupado hasta ahora y por otra parte han empleado fuertes cantidades en acondicionar la vivienda a su gusto y ahora temen que puedan perderlas al no hacer frente a la deuda (Uno de los problemas más gordos que tenemos en Cortegana es de las casas que tenemos, pues debemos una cantidad de dinero de los arriendos, porque cuando nosotros..., de que no íbamos a pagar tanto, nos pusieron una cuota muy arta a lo primero, nos pusieron unas ocho mil y pico, se nos ha acumulao mucho y debemos un dinero bastante serio. El otro día ya lo hablé, vuervo a decir otra vez, que yo quisiera a vé de que manera, bien por la Junta de Andalucía o por otros medios, que nos perdona- 
ran y no pusieran las casa a precio de coste, que las pudiéramos comprar y no que hay chavales que se han casao y a fecha de hoy, tenemos por lo menos unos veinte que están conviviendo con los padres... -Presidente de la Asociación Romaní 'Dom Dibé'-).

Mientras las casas de la calle Mendo se encuentran en muy malas condiciones y no se arreglan a pesar de ser propiedad de los gitanos que las habitan, los arreglos exteriores que se han hecho en las casas de la barriada Eritas han levantado la suspicacia de algunos de sus inquilinos, al denunciar que se ha hecho con dinero de la asociación gitana. Según su punto de vista, este dinero debía de tener otros fines y no consideran que eso haya sido en su beneficio, sino que piensan que ha sido una mejora para el pueblo pagada con dinero de su asociación (Los gitanos hacemos más por er pueblo, de la asociación que tenemos, que er pueblo por lo gitanos. Porque de la asociación de los gitanos se está arreglando muchas cosas der pueblo jeh!, ¡lo que er pueblo no arregla ná por lo gitanos! -Varón, 43 años, sin estudios, casado, tratante de bestias y temporero, de Cortegana-. Se han aprovechao de que ha estao aquí la asociación montá, pa poder con er dinero tapar cosas con la asociación, pintar las calles, pintar las paredes y arreglar las casas. -Varón, 45 años, sin estudios, casado, tratante de bestias y temporero, de Cortegana-).

El hacinamiento, sin lugar a dudas, es el mayor problema que encuentran con respecto a la vivienda junto con la dificultad de acceder a alguna, ya sea en propiedad o en alquiler. Hemos constatado bastantes casos en los que conviven varias generaciones con abundantes miembros. Entre las mujeres casadas de treinta años, la que menos tiene son seis hijos y las casadas con veinte años son ya madres de al menos dos niños, mientras que las más mayores cuentan con una media de diez o doce hijos. Si tenemos en cuenta que los nuevos matrimonios siguen surgiendo antes de cumplir los veinte años, y añadimos la dificultad de encontrar vivienda, podemos imaginar la situación y la incomodidad que se les plantea a todos los miembros de la familia, especialmente como nos recalcaron a los padres que tienen hijas solteras (Es indigno, es indigno de que un padre meta un matrimonio dentro de una casa con hijas casás, con hijas nuevas, solteras, que er que más que menos tiene dos o tres hijas y se tiene que acostar la mocita en la misma habitación con el casao. Es un respeto que nosotros tenemos que tener, por lo menos los gitanos llevamos esa ley, ese respeto, esa educación, que no debiera haber un matrimonio con una soltera en una habitación y jclaro, si no tenemos más remedio! -Varón, presidente de la Asociación Romaní 'Dom Dibé'-).

Quejas continuas radican en que no hay casas para alquilar o que, cuando existen, el precio de los alquileres es muy alto, aunque sin em- 
bargo se acepta que no es un problema privativo de la etnia gitana (Es que aquí no hay casa de arquiler, porque si hubiera casa de arquiler, argunos de ellos no estarían viviendo con los padres. -Mujer, 31 años, sin estudios, casada, ama de casa, de Cortegana-. Hay payos que están en el cuento nuestro o quizá peor. Incluso yo tengo un piso mu grande con cuatro habitaciones y yo me las veo.-Mujer, 31 años, sin estudios, casada, ama de casa, de Cortegana-).

Otra de las cuestiones planteadas hace alusión al hecho de hallarse ubicados mayoritariamente en una zona periférica, lo que les produce sensación de ghetto, aislamiento y mayor dificultad para cambiar de forma de vida, al menos según se deduce de los comentarios hechos por los jóvenes (¿Por qué nos han puesto casi tó los gitanos en una barriá? ¿por qué no han hecho un bloque de cuatro plantas en la mitad der pueblo, o bien donde quiera? Asquí uno pocos, en el centro otro pocos y asín nos repartimos entre toa la comunidad der pueblo. -Varón, 24 años, sin estudios, soltero, temporero, de Cortegana-. No, y como estamos tós los gitano juntos, pós semos tós los gitanos iguales. Si fuera estao repartio pa una esquina, otro en otra esquina, pós seremos ya diferente. -Varón, 18 años, sin estudios, soltero, temporero, de Cortegana-). Esta sensación de vivir en un ghetto se aprecia fundamentalmente al conocer la realidad de otros pueblos, tanto por los gitanos de Cortegana como por los que habitan en pueblos diferentes (Ustedes habéis tenido problemas, porque os han mandao a todos al mismo sitio, os han encerrao aquí y. jbueno! -Presidente de la Asociación Romaní Aracena-).

En cuanto a Galaroza, las viviendas en las que habitan familias gitanas, también se ubican en la periferia del pueblo -calle Valdelarco-y se encuentran en régimen de alquiler, son de planta baja y algo deficientes por lo que respecta a la imagen exterior. En Alájar hallamos una situación muy parecida, con casas de alquiler poco atendidas, en lo que se refiere a las fachadas. El hecho de que sean de alquiler viene provocado, en parte, por la falta de viviendas de promoción pública en ambos municipios, pero tampoco se aprecian deseos de compra.

Aracena, sin embargo, presenta una situación diferente y diversa. Las familias gitanas se hallan dispersas por todo el municipio, habitando en algunos casos viviendas de protección oficial en barriadas periféricas y multiproblemáticas como la Barriada 'Rafaela Flores'. No existe problema de hacinamiento, pero sí existen personas con dificultades para acceder a la propiedad de una vivienda, que alquilan, buscan ayuda en la asociación o a través de los servicios sociales. No hay queja de racismo, sólo de que no siempre se ayuda al más necesitado (jhombre! yo sé a quien se las dieron, a quien se las han dao y las conocía, además que eran vecinas mías, que las conocía.., 
yo lo tomé que no hay leyes iya está!, ;que no hay leyes! -Mujer, 37 años, estudios primarios, casada, ama de casa y jardinera, de Aracena-).

\subsection{Salud}

En cuanto al tema de salud y sanidad en su conjunto, destaca sobremanera el alto índice de discapacitados físicos y especialmente psíquicos que aparecen entre las comunidades gitanas de Cortegana y de Alájar. Al margen de los problemas de comunicación que pueden venir derivados de la falta de formación y del uso del lenguaje, se aprecian bajos índices de comprensión y de madurez a todos los niveles, junto con un alto porcentaje de enfermedades nerviosas (Es que hay mucha gente que a lo mejó no está loco, pero depende de los nervios. Yo, por ejemplo, dependo de los nervios. Cuarquiera que me vea, me dice que estoy loco, pero no, es que dependo de los nervios. Yo no dependo de mi cabeza igracias a Dios!', yo dependo de los nervios. -Varón, 18 años, sin estudios, soltero, temporero, de Cortegana-). No hay un concepto de salud integral ni siquiera amplio, en realidad se reduce mucho a la asistencia al médico o al Centro de Salud cuando los síntomas de enfermedad son ya muy evidentes, y aún así hay mucho recelo a la visita médica. Las vacunaciones han sido casi inexistentes, aunque están comenzando a regularizarse, gracias a la intervención del Programa de Desarrollo Gitano.

Es ampliamente reconocido, por ellos mismos, que en su comunidad se dan muchos casos de retraso mental y físico (mentalmente ;eh!, físicamente y mentalmente. Sí, sí, aquí hay más, me parece, que en ningún pueblo. En cada casa, mismamente yo tengo un tío que tiene dos, tengo otro primo hermano, que vive por debajo mia, tiene otros dos, tengo un cuñao que tiene otros dos, mi hermano tiene dos, éste tiene, yo tengo, casa por casa te abajarías tú y no se escapa.., uno me parece que se escapa, jes éste! -Varón, 45 años, sin estudios, casado, tratante de bestias, temporero, de Cortegana-), asumiéndolo como algo natural y achacándolo a factores fuera de su alcance, en los que por tanto no pueden intervenir, mostrando un carácter fatalista (Será por el clima o será por el ambiente o será por lo que sea, que la situación de los gitanos, hablando vulgarmente, hay muchas síntomas de retrasos mentales! -Varón, 45 años, sin estudios, casado, tratante de bestias, temporero, de Cortegana-).

Sin embargo, ese aire fatalista es una cobertura, ya que reconocen, por otro lado, el papel que la endogamia juega en esta situación ( $; Y$ Yo qué sé!, será por la sangre, porque somos más familia allegá y entonces eso influye. -Varón, 45 años, sin estudios, casado, tratante de bestias y temporero, de Cortegana-; esto es así, casi de herencia. 
-Mujer, 42 años, sin estudios, casada, ama de casa y temporera, de Cortegana-).

Al entender que es un problema de herencia, no le ven solución médica y, lo que es más grave, no hay interés en cambiar la situación. Ante eso, solamente nos dijeron que necesitan más ayuda económica, en lo que se refiere a aumentar el monto de las pensiones no contributivas por invalidez que de hecho ya perciben, casas más grandes y un mayor apoyo por parte del sistema educativo para la enseñanza de sus hijos (El mío lleva desde chequinino en la escuela y no le han enseñao ná, no le han puesto ni una maestra pa que le ayude, porque er niño no sabe ni hablar. -Mujer, 32 años, sin estudios, casada, ama de casa y temporera, de Cortegana-). No obstante, lo que ven absolutamente necesario es el mantenimiento de la pureza de la sangre gitana, aún a costa de la salud mental y física de sus descendientes (Porque los gitanos se casan con primas hermanas y de ahí vienen los problemas de minusvalía $y$ de retrasos mentales. Los gitanos se casan con una gitana. No quiero payas. No porque seamos racistas al payo. Nosotros queremos que nuestra trascendencia siga, que no se pierda la sangre gitana y si nos casamos con una paya, al final se pierde, porque ;se pierde!, pero ;vamos! los viejos queremos por tós los medios que no se pierda ; por lo menos! -Presidente de la Asociación Romaní 'Dom Dibé'-).

Otro factor que influye en la mala salud (tensión alta, exceso de resfriados..., como nos reconocieron en un alto porcentaje) es, sin duda, el desorden nutricional, provocado en gran parte por la costumbre, el desconocimiento general del tema y la mala administración que realizan de los recursos económicos y alimenticios, aún siéndoles en muchos casos facilitados por la Cruz Roja (Ahora cuando lleguen los alimentos de la Cruz Roja, ellos no saben qué hacer con esos productos y dicen: '¿qué hago con tantos macarrones?', por ejemplo, no le dan el uso. -Trabajadora social del P.D.G.-), de ahí que desde las responsables del Programa de Desarrollo Gitano se estén programando cursos de administración de recursós para amas de casa relativos, entre otros, a los hábitos alimenticios, elaboración de menús compensados y de higiene doméstica.

La ausencia de visitas a los médicos se debe a varios motivos. Por un lado, el temor y la vergüenza a lo que pueden decir los demás, y por otro, el pensamiento de que aquello que es de herencia no tiene solución, aunque fundamentalmente nosotros apreciamos que no hay verdadera conciencia de la gravedad de la situación de esta comunidad con relación a la salud (Yo creo también que es por vergüenza, de lo que dirán los demás gitanos -Mujer, 20 años, estudiante de bachillerato, soltera, de Aracena-y también por las mala lenguas, que si yo 
lo llevo ar médico, despué habla malamente de mi hijo, que si tiene una farta mala, que si está loco. -Mujer, 17 años, sin estudios, soltera, realiza tareas domésticas, ayuda en el cuidado de los animales y trabaja como temporera, de Cortegana-. No, hay gente que necesita, por ejemplo, de que lo lleve a los médico, porque a lo mejó tengo una farta en una pierna, ;lo que sea!, o er que está loco o farta, que no tenga er sentío de una persona normá y a lo mejó, po ello que, que es de herencia y lo tiene que dejá mal. -Varón, 24 años, sin estudios, soltero, temporero, de Cortegana-).

Antes de comentar la situación en otros pueblos de la sierra, queremos hacer mención a que una de las enfermedades detectadas entre esta comunidad, lo fue también en otros pueblos como Paymogo. Nos referimos a la Charcot Mary Tooth, de la que más tarde hablaremos.

Por lo que respecta a Galaroza y a Aracena, no existen entre sus comunidades gitanas problemas de salud dignos de mencionar, ya que su situación es totalmente comparable a la del resto de los habitantes de estos municipios, tan sólo nos encontramos con un caso de malformación física en Aracena. Por el contrario, Alájar presenta un panorama distinto, de catorce miembros que tiene su comunidad, cuatro son deficientes psíquicos declarados, uno físico, cinco con problemas importantes de alcoholismo y en su gran mayoría presentan acusados rasgos de retraso mental y madurativo.

\section{ANDÉVALO - CUENCA MINERA}

\subsection{Vivienda}

En Paymogo la población gitana se encuentra dispersa, aunque un amplio número de miembros de esta etnia habita en la zona conocida como Las Chozas. Un grupo de familias ha sido realojado en casas prefabricadas hasta que sus viviendas sean rehabilitadas, debido a las pésimas condiciones en que se encontraban (humedad, falta de luz y de ventilación, sin cuarto de baño y con un grifo de agua del que se surtían varias viviendas). Son de su propiedad como ocurre con la mayoría de las casas que habitan los gitanos de este municipio, aunque existen quince casas alquiladas también por ellos y dos familias han accedido a viviendas de promoción pública. Algunas familias no han sido reubicadas, pero sus casas están siendo rehabilitadas con subvenciones otorgadas por la Junta de Andalucía.

Las casas de los gitanos de Nerva no son de promoción pública y se hallan en muy malas condiciones. Habitan en los barrios de La Balsa, 
San José Obrero, Pozo Bebé y en el Cerro Pelambres. Antes habitaban todas en el Pozo Bebé, un barrio extremadamente pobre y de ambiente marginal, en el que se intervino para diseminar a la población. Otra familia ha ocupado una vivienda de promoción pública en La Balsa mediante el derribo de la puerta. En algunas casas no hay agua corriente y se dan casos de hacinamiento no sólo por el número de habitantes sino por la pequeñez de muchas de sus viviendas.

En Minas de Riotinto ${ }^{5}$ se concentran en la periferia -El Alto de la Mesa-, habitando en casas abandonadas, construidas tiempo atrás por la compañía minera para sus trabajadores. Son casas pequeñas, ocupan entre cincuenta y sesenta metros cuadrados, separadas en dos cuerpos. Salvo las dos primeras familias que llegaron al municipio y recibieron la llave de la compañía a principios de los años ochenta, en la mayoría de los casos se trata de ocupaciones ilegales, que han facilitado y aumentado el asentamiento. De las once familias reconocidas, dos proceden de Nerva y las demás están relacionadas entre sí, procediendo de Almonte, de Trigueros, de Linares, de Paymogo y de las Tres Mil viviendas de Sevilla. Una familia mixta habita al principio de la aldea de La Dehesa. Hay que tener en cuenta que el pueblo se ha ido desplazando a medida que la compañía encontraba un filón, con lo que El Alto de la Mesa también está ocupado por población gadje de la tercera edad. Encontramos hacinamiento en las familias quinquilleras y mixtas (gitanos - quinquilleros).

En Calañas la comunidad gitana se encuentra en la periferia pero dispersa por la zona norte del municipio, con casas bien acondicionadas, por lo general tanto en el exterior como en el interior. En El Cerro del Andévalo, se sitúan en una zona concreta, con viviendas de promoción pública, popularmente conocidas como las Casas Nuevas, pero sin problemas aparentes.

En Alosno hay siete familias, aunque en alguna conviven familias extensas, ubicadas en la calle Nueva, en la calle Perdida y en la Avenida de El Calvario, en una barriada de reciente creación con viviendas de promoción pública. Son casas bien equipadas. La comunidad gitana de Cabezas Rubias se encuentra dispersa por el municipio, en casas de su propiedad y bien acondicionadas.

\subsection{Salud}

Con respecto a este tema, el problema más importante lo encontramos fundamentalmente en el municipio de Paymogo, donde aparecie-

5 En este caso, debemos reseñar que aunque en el pueblo se habla de gitanos, la mayoría de las personas a las que se refieren son quinquilleros. 
ron múltiples casos en su comunidad gitana de personas aquejadas de retraso mental y de la Charcot Mary-Tooth, ésta última azotando especialmente a la población infantil. Esta enfermedad, descubierta hace más de cien años, consiste en un desorden neuromuscular que afecta fundamentalmente a las funciones sensoriales y musculares de las extremidades. En realidad, el nombre está tomado de los doctores franceses, Jean Martín Charcot y Pierre Marie, y del doctor inglés, Howard Henry Tooth, y engloba a varias enfermedades genéticas a las que también se conocen como neuropatías heredadas motoras y sensoriales (HMSN) ${ }^{6}$. Así mismo los Gitanos de Paymogo presentan graves deficiencias sanitarias debido a la mala alimentación y a la falta de equilibrio nutricional, al abuso del alcohol y del tabaco entre los varones, a la nula educación sexual y escasa preparación para el cuidado de los niños y a la poca importancia concedida a la higiene personal y de su hábitat. En este terreno está siendo importante la concienzuda labor desempeñada por el equipo del Programa de Desarrollo Gitano de este municipio. Nos fue comentado como se han producido avances, aunque muy lentos, en lo que se refiere a la concienciación de esta población para asistir a revisiones médicas en general, además de bucales y oftalmológicas. Uno de los problemas más importantes con que tienen que luchar la población de esta zona es los escasos servicios con que cuentan y su centralización en pocos municipios, lo que dificulta su acceso por las malas comunicaciones de que disponen (La falta de comunicación con el Centro de Salud que está a veinte kilómetros -en La Puebla de Guzmán-y no hay ni un autobús que vaya regularmente allí. - Trabajadora social del Programa de Desarrollo Gitano de Paymogo--).

En Calañas, la comunidad gitana no tiene enfermedades significativas aparte de los problemas con el alcohol y con las drogas de algunos de sus miembros. Nerva muestra un alto índice de malos tratos familiares que llega al $90 \%$, con alto grado de alcoholismo en los varones y consumo de hachís. Una familia muy extensa presenta cataratas congénitas y las van heredando todas las generaciones. La falta de higiene también es manifiesta, especialmente en las mujeres. En Minas de Riotinto aparece falta de higiene, malnutrición y algún caso de drogodependencia.

Aproximadamente dos tercios de las personas que poseen esta enfermedad tienen afectada la capa de mielina que protegen los nervios (tipo 1), mientras el otro tercio sólo tiene afectado las axonas o fibras de los nervios (tipo 2). Algunos hablan del tipo 3 cuando se trata de la Dejerine-Sottas -también deriva su nombre de los doctores franceses que la descubrieron a finales del siglo XIX, Joseph Jules Dejerine y Jules Sotas-, una variedad más aguda y severa de la CMT. El tipo 1 viene provocado por la anormalidad de los genes situados en los cromosomas 1,17 y X, mientras que para el tipo 2 aún no están muy identificados los genes, pero parece que se sitúan en los cromosomas 1 y 3 . 


\section{CINTURÓN AGROINDUSTRIAL}

\subsection{Vivienda}

En Moguer, la población gitana se encuentra dispersa por todo el municipio y el acondicionamiento de las casas es acorde con la situación económica de cada persona, en general gozan de muy buen estado y equipamiento. No suelen ser de promoción pública.

San Juan del Puerto tiene su comunidad gitana más concentrada, fundamentalmente en la barriada Juan Carlos Primero, en viviendas de promoción pública y bien acondicionadas. Otros habitan en casas dispersas por todo el pueblo. En Trigueros, la comunidad gitana también se encuentra diseminada en viviendas de promoción pública sin problemas aparentes, residiendo un importante número de ellos en la calle Pastora Pavón. Los gitanos de Aljaraque disfrutan de buena situación económica, lo que se refleja en sus viviendas, gozando además en ciertos casos, de casas ubicadas en zona residencial.

Palos de la Frontera no tiene comunidad gitana autóctona y, por lo tanto, los gitanos que residen en el municipio lo hacen de forma estacional procedentes fundamentalmente de la sierra o de fuera de España. Lo habitual es verlos formando sus acampadas, salvo casos minoritarios en que han alquilado alguna casa dentro del municipio, detectándose hacinamiento. Nos referimos a una familia que tras conflictos en Cortegana, decidió asentarse en Palos de la Frontera. Los campamentos mayoritarios se encuentran en la antigua carretera de Mazagón mostrando pésimas condiciones de habitabilidad.

Gibraleón mantiene su población gitana dispersa mayoritariamente en viviendas de promoción pública situadas en zonas periféricas, en concreto en las calles Príncipe Felipe, Maestro José Soto y en el barrio de San Rafael, conocido popularmente como Villalata. Otros han comprado terreno y han construido sus casas en el campo dentro del término municipal de Gibraleón.

\subsection{Salud}

En lo que se refiere a este tema, podemos afirmar que no hemos encontrado enfermedades específicas dentro de la comunidad gitana que sean dignas de señalar, salvo un caso de deficiencia mental en Moguer. Sin embargo, sí hemos encontrado numerosos casos de consumo de droga, especialmente en Gibraleón, y en menor medida en Trigueros, donde el alcoholismo es importante. 


\section{CIUDAD DE HUELVA}

\subsection{Vivienda}

Los gitanos de Huelva no se encuentran concentrados en un solo barrio, pero tampoco existe una gran dispersión en el sentido de que, salvo excepciones, la gran mayoría habita en barriadas periféricas, entre las que destacan por su número de población gitana la barriada de 'Alcalde Diego Sayago', popularmente conocida como el Torrejón, la barriada de la Orden, las barriadas encuadradas en lo que se conoce como Marismas del Odiel (Cardeñas, La Navidad, Hotel Suárez, el Carmen, el Chorrito, Las Colonias Los Dolores) y en las barriadas de Fuentepiña, Los Rosales y Pérez Cubillas, fundamentalmente. Otros puntos son la calle Rodrigo de Jerez y la Plaza de la Serrana.

Como anunciamos, el grueso de la comunidad gitana se afinca en barrios periféricos con características de clara marginalidad, algunos de los cuales registran todos los niveles de exclusión social con conductas asociales y antisociales. La cuestión del urbanismo es uno de los puntos más débiles de la ciudad, debido en parte a la proliferación de chabolas y casas autoconstruidas sin ningún control municipal que inundaron Huelva con la instalación del polo químico en los años sesenta. Personas de toda la provincia, sin cualificación profesional y con pocos recursos optaron por emigrar a la ciudad en vez de hacerlo fuera de la provincia o incluso de la comunidad andaluza como hicieron otros muchos. La avalancha supuso un verdadero caos urbanístico, que no se detectaba claramente en la época debido a las costumbres autóctonas, pero que con el tiempo ha aflorado a la superficie. Los intentos de readaptación del territorio van siendo numerosos en la última década, aunque con relativo éxito y menos aún cuando se han tratado procesos de reubicación (Es un proceso de reubicación de las personas en un entorno, que no está acompañado de un proyecto de acción social y fundamentalmente que no hay una adaptación del sistema de vivienda a las necesidades de la población con la que se va a trabajar. Es necesario hacer un estudio de población previa antes de hacer un plan urbanistico y atender a las necesidades de la población que se va a trasladar, se tendrá mayor éxito. -Trabajador social de los Serv. Sociales Municipales de Marismas del Odiel-).

Por otro lado, los procesos seguidos por estos barrios han sido de continuo deterioro alcanzando cotas realmente preocupantes, en algunos casos, por el aumento de la violencia, vandalismo callejero, tráfico de droga, lucha de perros adiestrados, robo de vehículos (Porque están muchos enganchaos con la plata y hay un montón de plata tirá por el suelo. Por mil pejetas se matan ahi tós. -Varón, 13 años, 
estudiante de ESO, de Huelva-. Hay muchas peleas de perro por el barrio, eso es guapo jquillo! -Varón, 12 años, estudiante de ESO-. Embucharlos a pelear eso es lo más guapo que hay, lo malo es que se te lance pa ti. -Varón, 13 años, estudiante de ESO, de Huelva-). Una queja constante, incluso de los más pequeños es la falta de actuación policial (Pero ¿pa qué quieren que vaya? jsi despué no hacen ná! y si te roban o argo, ni echan cuenta ni ná y los enganchaos no son los únicos esos, también hay de la policía, también son, hay enganchaos. -Varón, 13 años, estudiante de ESO, de Huelva-. Sí es verdad jeh!, hay enganchaos que son policías también. -Varón, 12 años, estudiante de ESO-. ¿Es que comen de ahí ellos? ¿Se llevan un porcentaje de la que vende? Porque si yo me pusiera a vender también droga, por ejemplo, no tardaría un día ni tres días y estaría cogío, por ejemplo, yo pienso así, yo te estoy diciendo mi opinión, y esa que lleva años $y$ años $y$ años $y$ años vendiendo y siempre vendiendo y jcomo vendiendo pipas!. Como he dicho antes, $y$ ahí está, ahí está vendiendo y lleva años y años y jahí está todavía ella!. ¿Y por qué no se la quitan?, porque el que hace la misma ley hace la trampa. ¡De ahi comen la mayoría de los policías!, porque jcomen! -Varón, 27 años, sin estudios, soltero, temporero, de Huelva-).

En conjunto todos estos barrios están conformados por viviendas de promoción social y algunas casas autoconstruidas, por lo tanto la mayoría de la población gitana de la ciudad de Huelva habita en este tipo de casas. El acondicionamiento es muy variado atendiendo, en muchos casos, a las posibilidades económicas de los propietarios, aunque suelen destacarse problemas de humedad, un creciente hacinamiento y dejadez por la imagen exterior de los edificios, cuando no franco deterioro, al priorizarse los símbolos de estatus económico como son los coches, las motos, las joyas y los aparatos domésticos.

También encontramos que mientras algunos que fueron reubicados en otras zonas de la ciudad, decidieron volver a sus barrios de origen, otros lo abandonan o desearían hacerlo pero se lo impide la estrechez económica (Si pudiera me iría a vivir a otro sitio, no por mí, no me gusta que mi hijo vea esos ambientes ${ }^{7}$.-Mujer, 34 años, sin estudios, separada, limpiadora, de Huelva-).

\subsection{Salud}

El problema de salud más acuciante que presenta la comunidad gitana de la ciudad de Huelva está relacionado de lleno con la droga.

\footnotetext{
Vive actualmente en la calle Honduras del barrio de Fuentepiña.
} 
No solamente hablamos de las personas que sufren la adicción a cualquiera de los estupefacientes ilegales, sino incluso a medicamentos que ayuden a sobrellevar la tensión de vivir en continuo riesgo de ser aprendido por la policía. Esto último se aprecia de forma considerable en las mujeres, repercutiendo de forma directa en la familia y especialmente en los niños, a los que se descuida en muchos casos (como hay mucho problema de droga aquí, que hay mucha gente metida, nosotros pensamos que no tienen tranquilidad, sino que tienen que estar pendientes que si viene la policía, que le van a hacer un registro, ahora que le van a hacer no sé qué, no sé cuanto, sobretodo le afecta muchas a las mujeres, y después toman muchas pastillas pa los nervios, pa la depresión y eso repercute, que no se levantan, que no son capaces de levantarse pa llevar a los niños al colegio. - Trabajadora social del Programa de Desarrollo Gitano de Huelva-).

Como era de esperar ante esa situación, encontramos enfermos de SIDA o portadores del VIH y entre los niños también se dan numerosos casos de bronquitis asmáticas, un alto índice de falta de vacunación (Con respecto a la salud, los niños gitanos no entran en el sistema de vacunaciones, unos entienden que si no tienen la enfermedad, ¿para qué se la va a meter? Otras veces por desectructuración y falta de conocimiento de los servicios públicos. Hay familias con problemas de todo tipo, incluidos los de salud, que sólo se atiende cuando aparece la situación crítica. Los niños que se vacunan es por una obligación a la integración en el colegio. Desde el Centro de Salud se hacen visitas domiciliarias que intentan llevar un control, pero de todas formas hay muchos que no lo hacen. -Trabajador social de los Serv. Sociales Municipales de Marismas del Odiel-). Se encuentran gripes y resfriados, junto con falta de higiene, en algunos casos, especialmente bucal (Hay algunos que llevan el chandall Nike y va con las manos sucias, no es problema de dinero, es problema de dejadez.-Monitora de los colegios Andalucía y Onuba-). Aunque no son muy significativos, también aparecen casos de síndrome de Down y de sordomudez. Por otro lado, las gripes, resfriados y enfermedades pulmonares son muy habituales en Huelva, debido a la marisma y a los altos índices de contaminación. Otro problema que encontramos es la mala alimentación, demasiados dulces, bocadillos y comida basura (Tienen problemas de salud, porque la alimentación no es la más adecuada o porque hay otros hábitos o posibilidades alimenticias. -Educador de calle del Centro Social 'El Torrejón'-). 


\section{CONCLUSIONES}

En la actualidad, la mayoría de la población gitana onubense cuenta con asentamiento fijo, aunque nos hemos encontrado con un importante número de ellos que se podrían calificar de seminómadas, ya que pasan varios meses fuera del hogar y en el caso concreto de la comunidad gitana de Cortegana, prácticamente todos sus miembros viven entre siete y ocho meses fuera de su domicilio oficial. Se alegaron diferentes motivos como la falta de trabajo por motivos de racismo, algo que por otra parte no fue compartido por gitanos asentados en municipios cercanos. Como decíamos, la cuestión del seminomadismo sin llegar al extremo de pasar más de la mitad del año fuera de casa, se observa en otros contingentes de gitanos onubenses, si bien son situaciones que pudieran fácilmente ser aparejadas con las vividas por gadje que deciden abandonar su lugar de residencia por motivos laborales. Los trabajadores temporeros forman parte de la rutina laboral de Huelva, sobre todo en la época de recogida de fresa o de naranjas, con lo cual no puede considerarse una característica peculiar del ámbito gitano. Bien es cierto que la escasa formación que presenta el colectivo gitano no le permite la entrada laboral en campos en los cuales se exige una mayor capacitación profesional y en este sentido sí puede decirse que es significativo el número de ellos que se dedican a estas labores, no obstante es sintomático de cualquier miembro de la sociedad gitana o no gitana que pertenece a la considerada clase media baja o baja.

Indiscutiblemente, atendiendo a lo observado en el conjunto de la provincia y a lo expresado por los profesionales encargados de la atención en los servicios sociales, la característica más sobresaliente es la integración de la comunidad gitana en el ámbito social de la provincia. Dejando de lado la escasa minoría que se mueve en ambiente marginal y/o ilegal, la amplía mayoría de los gitanos onubenses se encuentra imbricado sin dificultad en el entorno en el que vive. Cuando hemos encontrado diferencias entre los gitanos de un municipio y otro, ha sido constantemente un reflejo de las diferencias que existen de forma general entre esos dos municipios. No obstante, sigue habiendo un conjunto de pautas de comportamiento arraigadas en el mundo gitano que lo separan del grueso de la población. Nos referimos a pautas culturales como es la edad de entrada al matrimonio (varios años antes de la edad media de entrada del resto de la población), a la importancia concedida a la virginidad de la mujer, al cuidado de los hijos (algo muy discutible desde otros enfoques por las formas no por los contenidos), el sentido del honor (igualmente discutible), la pérdida de la pureza racial, y multitud de otros aspectos que señalan diferencias, muchas veces más provocadas por la intención que desde la naturalidad. Tam- 
poco resulta ajeno a ello, desde hace pocos años, la influencia de la iglesia evangélica.

El tema de la natalidad sigue siendo de gran trascendencia dentro de la población gitana. Como es lógico, si los matrimonios se producen a edad temprana, el periodo genésico de las mujeres es más amplio que el de sus congéneres gadje, por lo que ha habido lugares donde nos hemos encontrado con mujeres que no sobrepasan la veintena y ya son madres de dos o tres hijos. Evidentemente en este capítulo se sobreponen razones culturales con falta de formación sexual y presión por parte del entorno cercano familiar y religioso. Todavía resulta difícil concebir una mujer de respeto con una mujer que no ha sido capaz (el hecho de no desearlo es aún más excepcional) de engendrar hijos. Por otra parte, la falta de información y formación en el terreno sexual no va alejada sino paralela con las mismas en el terreno de la salud en su conjunto. Temas como prevención son aún difíciles de asimilar por parte de un grupo importante de este colectivo, de ahí la queja continua de los servicios sanitarios que deben atenderlos fundamentalmente en las salas de urgencias. Aquí de nuevo se une la falta de información sobre el funcionamiento de los servicios de salud con la comodidad de ser atendidos sin esperar las colas o realizar todos los trámites exigidos paso a paso por los centros, sin olvidar el componente cultural que no genético de la medida del tiempo. La realidad vivida por el gitano del aquí y ahora ha formado parte de los tópicos extendidos y sobrealimentados, en algunos casos, por ellos mismos. Así mismo, la influencia de los componentes culturales se ponen de manifiesto en este campo y de forma claramente sintomática, en el hecho de habernos encontrados con un importante número de personas gitanas que preferían la pureza de raza a la salud más elemental. Nos referimos a los casos, no pocos, que hemos observado de retraso mental o de enfermedades de carácter neuropatológico, una de cuyas causas es claramente la endogamia matrimonial tradicional. En el otro extremo han aparecido gitanos que declaran ser incapaces de comprenderlo, pero como era de esperar esto ha sido en las comunidades donde la interacción gitano / no gitano y los matrimonios mixtos son habituales.

Siguiendo con el tema de salud y con respecto a enfermedades concretas, junto con los retrasos mentales y las atrofias ya señaladas, debemos destacar los problemas relacionados con el consumo y el tráfico de drogas. En este caso, es justo señalar que no es ni un problema específico del gitano onubense ni exclusivo de este colectivo. Realmente y a lo largo de nuestro estudio hemos comprobado como este problema queda circunscrito a zonas muy concretas de ambiente urbano fundamentalmente, por otra parte de sobra conocidas, y que con riesgo de simplificar en exceso se encuentra muy definido en lugares 
como Isla Cristina y Huelva capital. El consumo de droga en la cuenca minera y en el Andévalo va en recesión por lo que respecta a la heroína, aunque pueden observarse aún los estragos que produjo en años anteriores. Lógicamente no ha escapado a ello la población gitana y hemos conocido casos de mujeres gitanas trabajando en la prostitución para el mantenimiento del hábito o de la pareja con problema de adición. En la ciudad de Huelva también resulta problemático el número de mujeres que padecen enfermedades nerviosas e insomnio como consecuencia de su adicción a la droga o, de forma más habitual, de la tensión mantenida ante una posible redada policial. Desgraciadamente, esto repercute no solamente en la vida personal sino en la vida familiar, atención a sus labores o cuidados de los hijos. La educación de los niños en ambientes de tráfico de droga está ofreciendo resultados difíciles de reconducir, pues el principal problema lo plantea la escala de valores en la que se mueven.

No debemos olvidar por otra parte que este tipo de situaciones se dan generalmente en zonas o barrios de las ciudades que suelen ser conocidos por no poseer las mejores condiciones de habitabilidad de la ciudad. La población que habita estas zonas suele caracterizarse por detentar un nivel socioeconómico bajo, con escaso nivel de formación y ocupando puestos laborales que ofrecen pocas posibilidades de acceder a viviendas de precios altos. En muchos casos las viviendas son de promoción pública. En este sentido, sí podemos afirmar que la gran mayoría de los gitanos que hemos conocido durante el periodo de la investigación en toda la provincia residen en este tipo de barrios. Aparte de la situación económica, que no siempre es baja, encontramos la resistencia a abandonar el barrio por la cercanía de otros familiares que es algo bastante querido en el mundo gitano. También es cierto que incluso cuando el nivel económico es alto, no suele corresponderse con niveles formativos altos ni amplias relaciones sociales con la sociedad mayoritaria, lo que supone otro óbice al abandono del lugar. Por supuesto, todo ello sin entrar a analizar a aquellos con alto poder adquisitivo, pero que por la ilegalidad de sus actividades no son bienvenidos dentro de otras áreas de la ciudad.

En conjunto, como advertimos, no hay grandes diferencias entre la situación sanitaria y condiciones de hábitat de los gitanos onubenses y sus vecinos gadje de la misma condición socioeconómica en sus municipios. 


\section{BIBLIOGRAFÍA}

ACTON, T.: Gitanos. Espasa Calpe. Madrid. 1983.

ALBAICÍN, J.: 'La simbología olvidada del gitano. Integrismo frente a integracionismo' en I Tchatchipen. No3. julio-septiembre 1993.

ALEMÁN BRACHO, C. y GARCÉS FERRER, J.: Politica Social. McGraw Hill. Madrid. 1997.

ARDÉVOL, E.: 'Dictamen sobre convivencia y relaciones interétnicas' en VVAA: Estudio Sociológico de los gitanos. PASS. Madrid. 1991.

ASOCIACIÓN BARRÓ.: Relatos de gitanas. Editorial Popular. Madrid. 1998 ASOCIACIÓN DE ENSEÑANTES CON GITANOS.: La diversidad culturaly la literatura. Boletín del Centro de Documentación de la A.E.C.G. n 13.Madrid. 1997.

AUZIAS, C: Les tsiganes ou le destin sauvages des Roms de l'Est. Michalon. Paris. 1995.

BERTHIER, J.C.- 'La socialización del niño gitano' en Revista Internacional de Ciencias Sociales $N^{\circ} 31.1979$. pp. 409-426

BLOCH, J.- Los Gitanos. Universidad de Buenos Aires. Buenos Aires. 1962

BLOCK, M.- Die Zigeuner: Ihr Leben und Ihr Seele. Bibliographisches Institut. Leipzig. 1936.

BORROW, G.H.-Los Zincali. Turner. Madrid. 1979.

BOTEY, F.: Lo gitano: una cultura folk desconocida. Nova Terra. Barcelona. 1970.

CABELLO, J.: Acción educativa compromiso social. V Congreso de Antropología. Alicante. 1987.

CALVO BUEZAS, T.: El racismo que viene: otros pueblos y culturas vistos por profesores y alumnos. Tecnos. Madrid. 1990.

CARMONA FERNÁNDEZ, A.: 'La identidad gitana' en Gitano. A fondo. No 11. Enero 2002. http://www.asgg.org/11a_fondo.htm

CAZORLA PÉREZ, J.: "Algunos sectores marginados en Andalucía" en Revista de Estudios Regionales No 28, pp3-25. 1990.

CECCHETTO, S.: Vasectomía: motivaciones históricas y cuestionamientos morales en http://www.bioetica.org/doctrina13.htm

CEUMT.: Estudio sociosanitario de la comunidad gitana chabolista residente en Andalucia. 1990.

CLEBERT, J.P.: Los gitanos. Ediciones Orbis. Barcelona. 1985.

CONCLUSIONES DE LA SUBCOMISIÓN PARA EL ESTUDIO DE LA PROBLEMÁTICA DEL PUEBLO GITANO. Diario de Sesiones del Congreso de los Diputados. 15 de diciembre de 1999.

CROWE, D. y KOLSTI, J.: The Gypsies of Eastern Europe. Armonk. New York. 1991. 
DEVALDÉS, M.: La maternidad consciente. Ed. Iniciales. Barcelona. 1929.

DRUKER, J.: "Making Romani Rights a European Issue" en Patrin: http:// www.geocities.com/Paris/5121/gheorghe.htm

EDITORIAL: 'Gitanos, estereotipos...y cintas de vídeo' en Gitanos, Nº 10. Junio 2001.

FRASER, A.M.: The Gypsies. Blackwell. Oxford. 1992.

GAMELLA, J.F.: Mujeres gitanas. Matrimonio y género en la cultura gitana de Andalucía. Junta de Andalucía. Sevilla. 2000.

GÓMEZ GARCÍA, P.: 'Las razas: una ilusión deletérea' en Gazeta de Antropologia, No 101993.http:/www.ugr.es/pwlac/G10_01Pedro_Gomez_Garcia.html

GUY, W. (ed): Between past and future: the Roma of central and Eastern Europe. University of Hertfordshire Press. 2001.

INFORME DE LA SUBCOMISIÓN PARA EL ESTUDIO DE LA PROBLEMÁTICA DEL PUEBLO GITANO. Boletín Oficial de las Cortes Generales del Congreso de los Diputados. 17 de diciembre de 1999.

IZARD, M.: Marginados, fronterizos, rebeldes y oprimidos. Serbal. Barcelona. 1985.

JIMÉNEZ, N.: La postura gitana ante la integración. Universidad Autónoma de Madrid. Madrid. 1994.

JORNADAS DE REFLEXIÓN SOBRE EL PUEBLO GITANO. Madrid. Junio 1997.

LAGUNAS ARIAS, D.: 'La presencia en el mundo. Alianza y reproducción entre los “calós" catalanes' en Gazeta de Antropología, No 17. 2001.http:/ /www.ugr.es/pwlac/G17_29David_lagunas_Arias.html

LAGUNAS ARIAS, D.: 'Resolviendo la salud. Los gitanos catalanes'en Gazeta de Antropología $\quad N^{\circ}$ 15.1999. http://www.ugr.es/pwlac/ G15_12David_lagunas_Arias.html

LINARES, E. y OLIETE, F. (coord.).: La protección juridica de las personas en situación de exclusión. Marco General. Cáritas Española. Madrid. 1999.

LÓPEZ HERNÁNDEZ, F.M.: Condición marginal y conflicto social. Talasa. Madrid. 1999.

McKEE, M.: 'The health of the Gypsies' en Patrin: http://www.geocities.com/ Paris/5121/healthuk.htm

MCLANE, M.F.:Proud Outcats: The Gypsies of Spain. Carderock Press. Cabin John. 1987.

OKELY, J.: The travellers gypsies. Cambridge University Press. Cambridge. 1983.

P.A.S.S.: Asentamientos gitanos en Andalucia Oriental. Secretariado General Gitano. Madrid. 1985.

P.A.S.S.: Estudio sociológico sobre la comunidad gitana en España. Marco teórico. Mimeo. Madrid. 1991. 
PÉREZ CASAS, A.: Los gitanos y las cuevas en Granada en http://www.ugr.es/ -pwlac/G01_01 Angel_Perez_Casas.html

PÉREZ, M.A. et al.: Salud materno-infantil. Intervención sobre vacunaciones con agentes comunitarios en población marginal gitana. Escuela Andaluza de Salud Pública. Granada. 1995.

PLANINTEGRAL PARA LA COMUNIDAD GITANA DE ANDALUCÍA. Secretaría para la Comunidad Gitana. Dirección General de Acción e Inserción Social. Consejería de Asuntos Sociales. Junta de Andalucía. Sevilla. 1998. PLAN NACIONAL DE ACCIÓN PARA LA INCLUSIÓN SOCIAL DEL REINO DE ESPAÑA. Junio 2001-03. Ministerio de Trabajo y Asuntos Sociales. Madrid.

PROGRAMA PARA EL DESARROLLO DEL PUEBLO GITANO. Subdirección General de Programas de Servicios Sociales. Dirección General de Acción Social, del Menor y de la Familia. Secretaría General de Asuntos Sociales. Ministerio de Trabajo y Asuntos Sociales. Madrid. 1997.

RAMÍREZ HEREDIA, J. de D.: Nosotros los gitanos. Ediciones 29. Barcelona. 1983.

RAMÍREZ HEREDIA, J. de D.: Vida gitana. Ediciones 29. Barcelona. 1973.

RODRÍGUEZ, J. et al.: Marginación e Intervención Social. Actuaciones y Necesidades de Colectivos en Riesgo de Exclusión Social en http:// www.cfnti.net/integra/jiry/pueblo/margin.htm

SAN ROMÁN, T.: Vecinos gitanos. Akal. Madrid. 1976.

SÁNCHEZ QUIJANO, A. y LISSEN, E.: 'Los gitanos y otros grupos de riesgo para el virus de la hepatitis B' en Medicina Clínica, 89 (13), pp549-550.

TORRES FERNÁNDEZ, A.: Historias de vida. Inédito. 1994.

TORRES FERNÁNDEZ, A.: Vivencias Gitanas. Instituto Romaní. Barcelona. 1991.

V.V.A.A.: Proyecto "Barañi" en http://www.jet.es/gea21/indice.htm

VEGA CORTÉS, A.: Los gitanos en España en http://www.unionromani.org/ histo.htm 